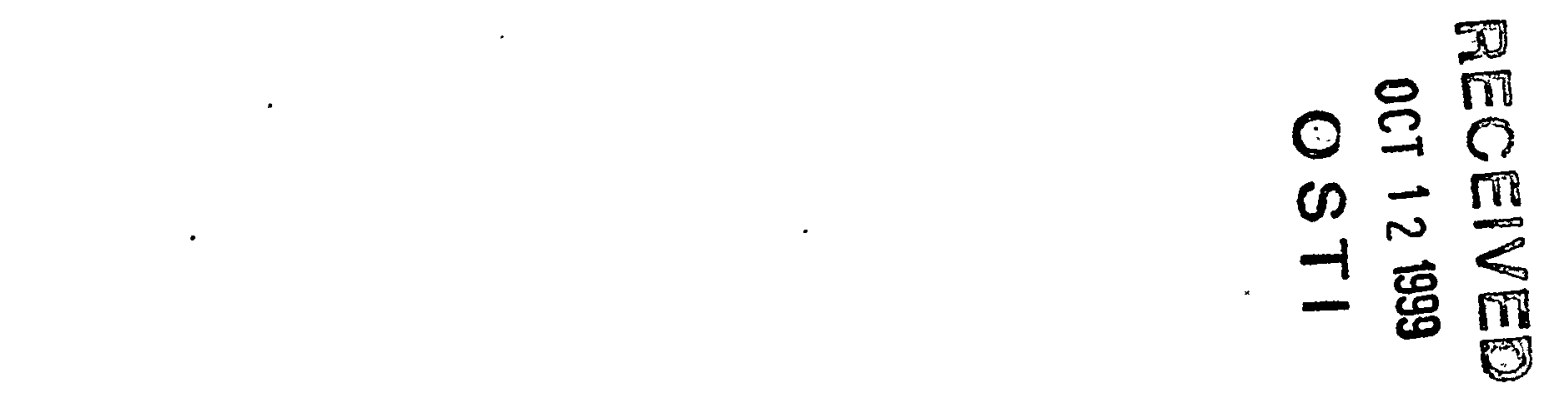

\title{
CHARACTERIZATION OF DEEP TUNNELING ACTIVITY THROUGH REMOTE-SENSING TECHNIQUES
}

R.G. Best, P.J. Etzler, and J.D. Blohm

Remote Sensing Laboratory 


\section{DISCLAIMER}

This report was prepared as an account of work sponsored by an agency of the United States Government. Neither the United States Government nor any agency thereof, nor any of their employees, make any warranty, express or implied, or assumes any legal liability or responsibility for the accuracy, completeness, or usefulness of any information, apparatus, product, or process disclosed, or represents that its use would not infringe privately owned rights. Reference herein to any specific commercial product, process, or service by trade name, trademark, manufacturer, or otherwise does not necessarily constitute or imply its endorsement, recommendation, or favoring by the United States Government or any agency thereof. The views and opinions of authors expressed herein do not necessarily state or reflect those of the United States Government or any agency thereof. 


\section{DISCLAIMER}

Portions of this document may be illegible in electronic image products. Images are produced from the best available original document. 


\title{
Characterization of Deep Tunneling Activity Through Remote-Sensing Techniques
}

\author{
R.G.Best, P.J.Etzler, and J.D.Blohm \\ Bechtel Nevada Remote Sensing Laboratory, \\ Las Vegas, Nevada
}

\begin{abstract}
This work is a case study demonstrating the uses of multispectral and multi-temporal imagery to characterize deep tunneling activity. A drainage tunnel excavation in Quincy, MA is the case locality. Data used are aerial photographs (digitized) and Daedalus 3600 MSS image data that were collected in July and October of 1994. Analysis of the data includes thermal characterization, spectral characterization, multi-temporal analysis, and volume estimation using digital DEM generation. The results demonstrate the type of information that could be generated by multispectral, multi-temporal data if the study locality were a clandestine excavation site with restricted surface access.
\end{abstract}

\section{Introduction}

Tunnels and underground excavations have been a favorite place to hide clandestine operations from prying eyes throughout history. Even today, this low-tech approach remains an effective means of concealment. The thick overburden and stability of the underground environment continue to confound intelligence-gathering operations, especially where surface access is limited.

Remote-Sensing has been applied to identifying and characterizing tunneling activity since the earliest aerial photographs. The primary means of gathering information has been by manual photo-interpretation. Since early photointerpreters could not see through the overburden, examining entrances of tunnels has been the traditional approach. More recently, thermal infrared imagery has been used to directly map underground features such as caves (Rinker, 1975) and waste disposal sites (Zilioli et al., 1992). Such direction requires special circumstances and becomes less useful as tunnel depth and overprinting surface clutter increases. For deep tunneling, answering questions such as: "How deep is it?" "How big is it?" and "Where does it go?" has remained problematic.

The purpose of this study is to demonstrate useful techniques for using modern, digital remote-sensing data to find better answers to the above questions as well as additional ones.

\section{The Quincy Site}

The Quincy Town Brook tunnel, the deep tunneling example used for this study is located in Quincy, Massachusetts, which is an urban suburb located 15 kilometers (9.4 miles) south-southeast of Boston (Figure 1). This example is a relatively deep tunnel of known proportions and location. It is also easily accessible and has no classification or security concerns. (U.S. Corps of Engineers Design Memorandum, 1994 - V.J. Murphy Personal Communication)
The Corps of Engineers Town Brook project is a flood control project in which a tunnel will be used to carry floodwater which exceeds the capacity of the Quincy, MA Town brook during heavy rains. The water will be diverted into a tunnel when floodwater exceeds the height of an overflow structure being constructed at the intake end of the tunnel. The Town Brook project is comprised of an intake shaft, an outlet shaft, and the connecting tunnel (Figure 2). At the intake, the tunnel will be approximately 46 meters (151 ft) below mean sea level and will fall to about 47 meters (154 ft) below mean sea level at the outlet. Both the intake and outlet shafts are 6.7 meters $(22 \mathrm{ft}$ ) in diameter. The tunnel is being constructed using a tunnel boring machine which was assembled at the outlet end and will bore in a southwesterly direction toward the intake shaft. The tunnel will be bored to a diameter of 4.3 meters $(14 \mathrm{ft})$ and finished to a diameter of 3.7 meters $(12 \mathrm{ft})$. The tunnel itself is roughly 1.2 kilometers ( $3 / 4$ mile) long. It is being cut through granite and argillite. (U.S. Corps of Engineers Design Memorandum, 1994 - V.J. Murphy Personal Communication)

The surface elevation of the tunnel site varies from 0 . to about 12 meters ( 0 to $40 \mathrm{ft}$ ) above mean sea level. The tunnel itself is drilled completely through bedrock, which lies 4.5 to 30 meters ( 15 to $100 \mathrm{ft}$ ) below the ground surface. The layer of soil which overlies the bedrock and is exposed at the surface consists of sands, gravels, and silts. The heavily urbanized area over the tunnel features such structures as four-lane highways, commercial and residential city streets, commercial and residential buildings, and the surface flow of the Town brook. (U.S. Corps of Engineers Design Memorandum, 1994 - V.J. Murphy Personal Communication)

\section{Collection}

The data analyzed for this study were collected as part of the AMPS (Airborne Multisensor Pod System) program (O'Connell et al., 1995). Two collections over the 

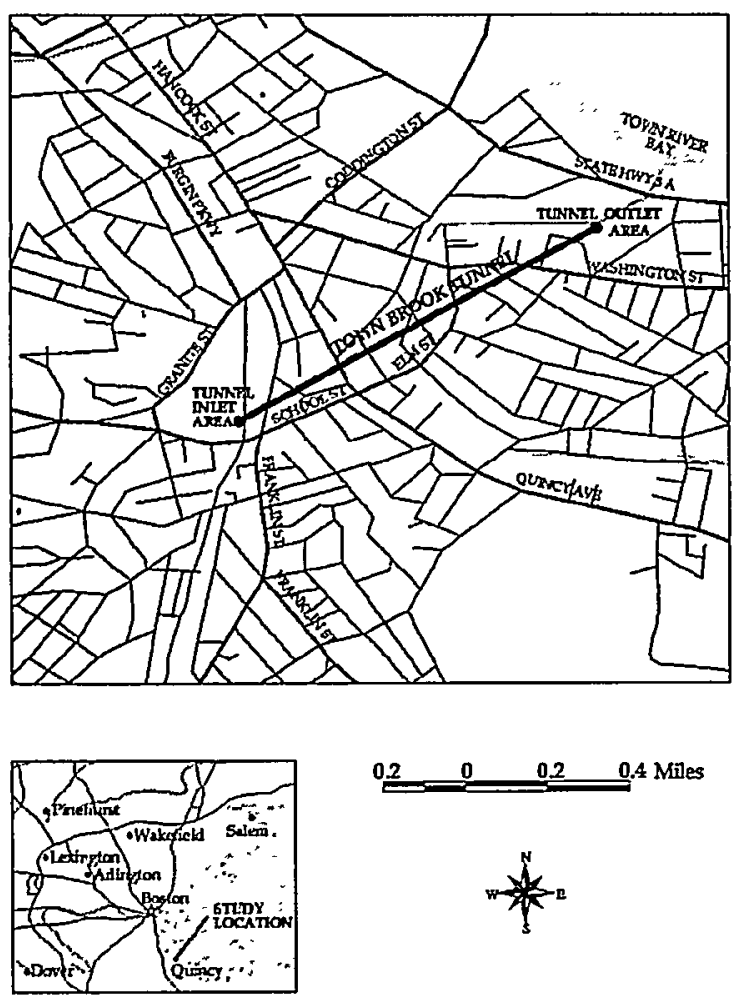

Figure 1. Location of the Quincy Town BrookFlood Control Project.

area of interest facilitate multi-temporal study. Imagery was collected as part of AMPS mission 3 on July 11, 1994 and AMPS mission 5 on October 16, 1994. Imagery used as part of this study was collected as CIR (Color InfraRed) aerial photographs by a Wild RC30 aerial mapping camera and digital, multispectral data collected by a Daedalus 3600 MSS (MultiSpectral Scanner) scanner. Photographs and scanner data were collected at the same time.

The Daedalus 3600 MSS scanner is a passive electrooptical system designed to collect and record reflected and emitted electromagnetic energy from the earth's surface. The MSS separates incoming radiation onto two optical ports covering (1) the visible to NIR (Near InfraRed) and (2) thermal infrared portions of the electromagnetic spectrum. The MSS can collect data in a maximum of six selectable bands out of twelve available spectral bands ranging from $0.42 \mu \mathrm{m}$ to $12.05 \mu \mathrm{m}$. Information describing this scanner (AA3600M1) can be obtained from Daedalus. Enterprises, Inc., P.O.Box 1869, Ann Arbor, MI 48106, (313)769-5649

The AMPS project collected data over the Quincy site twice, flying several passes during each acquisition date. The inlet (intake) and and outlet ends were covered during the July flyover. The October flyover covers the outlet only.

\section{Selection}

The highest resolution MSS imagery acquired was chosen for this study. This imagery was collected at an altitude of 457 meters $(1500 \mathrm{ft}$.) which gives a pixel size (GSD) of 1.14 meters ( $3.75 \mathrm{ft}$. ).

A different suite of MSS spectral bands was collected during each mission. The July mission used MSS bands $5,7,8$, and 10 , while the October mission used bands 2, 5 , and 8 (Table 1). MSS bands 5 and 8 were the only bands selected for both missions. CIR aerial photographs collected simultaneously with the MSS data were digitized into three bands (green, red, and NIR) to increase the number of common spectral bands between the July and October missions. All digitized photographs and MSS data were then co-registered so data fusion was possible and direct comparisons between the different data sets could be made.

\section{Analysis}

Preliminary investigations of the Quincy Town Brook tunnel site show that the tunnel is too deep and/or the overlying land use too complex to allow direct investigation along its path using remote-sensing techniques and the available imagery. Construction activity, however, is clearly present at both the inlet and outlet ends of the tunnel (which are clearly exposed). This construction activity occurs in both the July and October scenes. The two dates show a clear difference in the arrangement and equipment employed by the tunnel constructors - revealing a change of stage in the tunnel construction. The purpose of this study, however, is not to rely on just the spatial information but to demonstrate the additional capabilities that the multispectral and multi-temporal nature of the imagery provide to the investigator. Four examples of these capabilities are discussed below.

\section{Thermal Characterization}

Measurements in the thermal infrared region can sometimes see through objects that are opaque to visible light. Cursory examination of thermal infrared imagery confirms that the Town Brook tunnel does not exhibit an identifiable signature along its path, presumably because of its depth. The inlet and outlet openings of this tunnel, however, can be detected as they clearly show up as thermal anomalies.

Figure 3 compares the thermal infrared data alone with an image (right) made from the complete 3-band set 

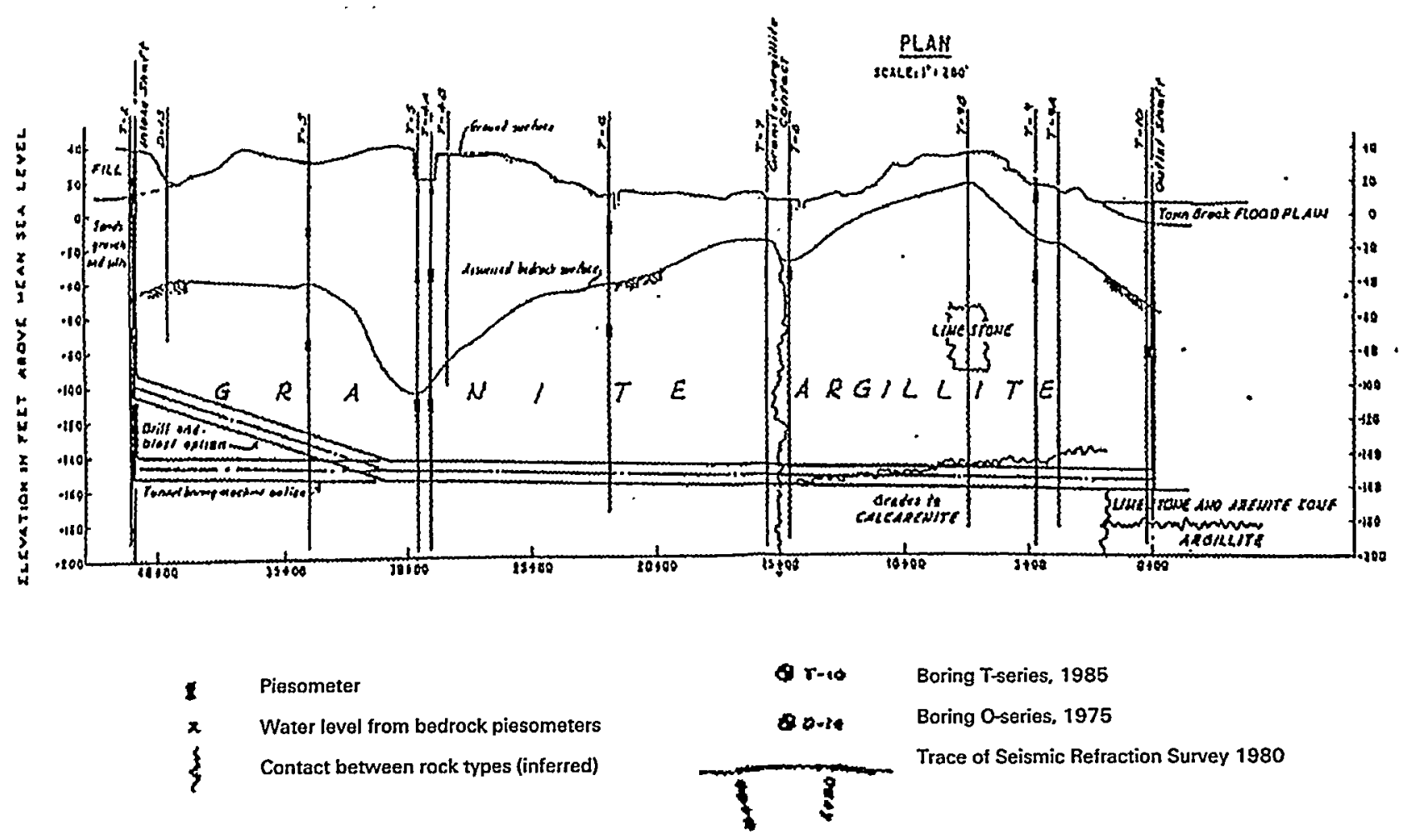

Figure 2. Topographic and Geologic Profile Along the Line of the Town Brook tunnel (After U.S. Corps of Engineers Design Memorandum, 1994).

of MSS data collected for the July data set. This false color image corroborates that the signature of the tunnel opening is unique simply because it is very dark in all three bands. A dark appearance would be expected because we are looking deep into the cool and dark interior of the tunnel, not the warm, sunlit surface. The image on the left eliminates the reflective light measurements and confirms the unique thermal signature of the tunnel opening. A level-slice highlighting the darkest (cooler) pixels in the image as red shows that, except for a few scattered pixels on building roofs (possibly areas of low emissivity - such as bare, shiny metal or standing water), the tunnel opening is uniquely cool. This figure is a single example, but suggests that thermal infrared surveys could be very useful for identifying tunnel openings, especially in cluttered areas like the Town Brook tunnel site. Comparisons with the false color image on the right show that the level-slice method makes identification of the tunnel much easier.

\begin{tabular}{||c|c|c|c||}
\hline \multicolumn{2}{|l|}{ Table 1: Daedalus 3600 MSS scanner bands. } & Lab results in microns \\
\hline \hline Channel \# & Color Spectrum & Manufacturer value in microns & $0.42-0.44$ \\
\hline \hline 1 & Violet/Blue & $0.42-0.45$ & $0.45-0.51$ \\
\hline 2 & Blue/Green & $0.45-0.52$ & $0.52-0.60$ \\
\hline 3 & Green/Yellow & $0.52-0.60$ & $0.60-0.64$ \\
\hline 4 & Orange & $0.60-0.63$ & $0.63-0.69$ \\
\hline 5 & Red & $0.63-0.69$ & $0.70-0.77$ \\
\hline 6 & Red/NIR & $0.69-0.75$ & $0.76-0.91$ \\
\hline 7 & Near Infrared & $0.76-0.90$ & $0.91-1.04$ \\
\hline 8 & Near Infrared & $0.91-1.05$ & $3.0-5.4$ \\
\hline 9 & Mid Infrared & $3.0-5.5$ & $8.4-14.5$ \\
\hline 10 & Thermal & $5.5-14.0$ & \\
\hline
\end{tabular}


Thermal infrared imagery could be utilized to locate tunnel openings even if some openings were covered.

Thermal anomalies would occur because the openings would release air from the typically-cooler, constant-temperature air within the tunnel (Rinker, 1975) to the surface with its diurnal temperature variations.

\section{Spectral Characterization}

The power of multispectral analysis can be applied to determine the spectral characteristics of surface materials. Each material has its own unique spectral signature. If the reflectance of a material is sampled at several wavebands, comparison with reflectances of known materials can identify the material in question. In multispectral data, each pixel is an integrated measurement of the reflectance of the surface materials with the instantaneous field of view of the collecting instrument. Before the data values can be compared to true reflectance measurements, all data must be calibrated to eliminate effects such as atmospheric transparency and instrument gain settings.

If a multispectral scanner collects data in correct wavebands, distinguishing characteristics within the resultant spectra can be used to identify materials removed from tunnel excavations. Knowledge of the general geology of an area with tunnels can be used to identify the rock type of tailings piles. Identifying the rock type can give information on where the material was removed within a tunnel. This information can answer questions such as tunnel depth or the direction a tunnel runs from a surface opening.

Figure 3. Thermal Characterization of the Tunnel Inlet.

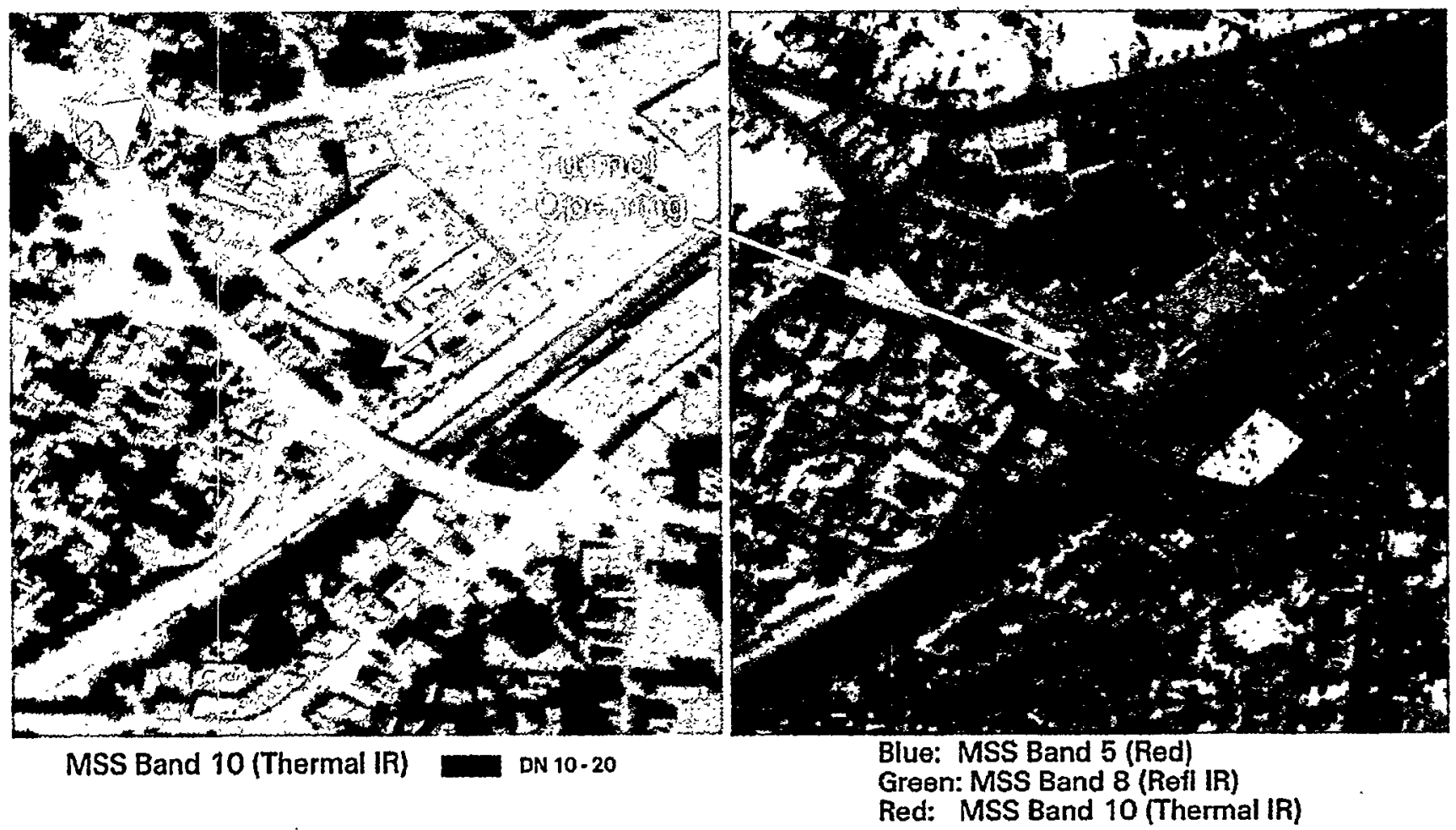

\section{Quincy, MA Town Brook Tunnel Site - Inlet End AMPS Mission 3, 11-Jul-94 Altitude: $1500 \mathrm{ft}$.}


Figures $4 \mathrm{a}$ and $4 \mathrm{~b}$ show laboratory spectra of rocks similar to those bored through by the Quincy Town Brook tunnel. Superimposed over these spectra are the wavebands of Daedalus MSS bands 5 and 8, the two MSS bands common to the July and October collections. Comparison

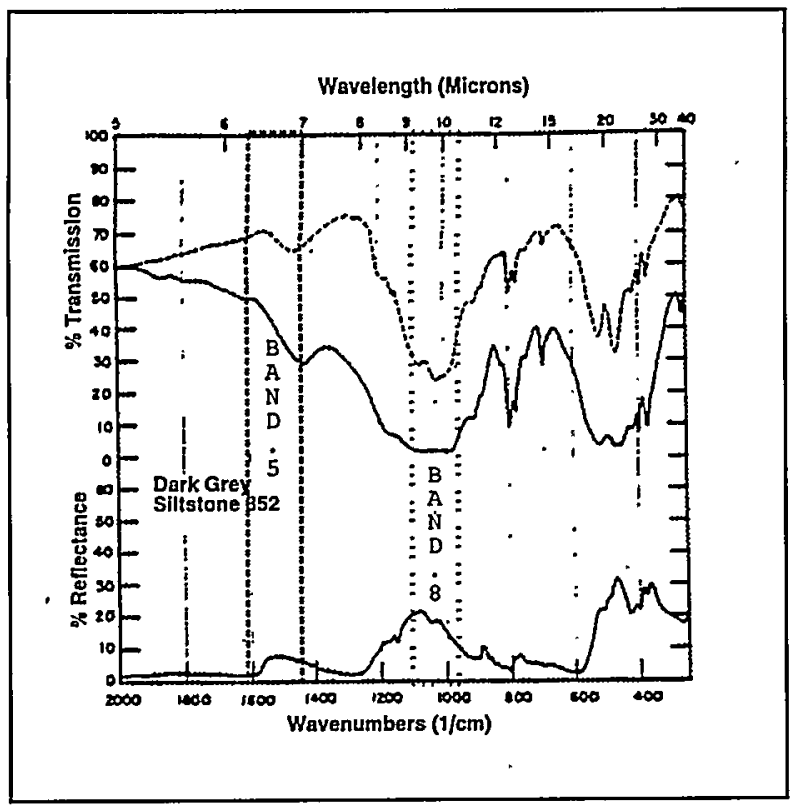

Figure 4a. Spectrum of Dark Gray Siltstone (after Hunt and Salisbury, 1975).

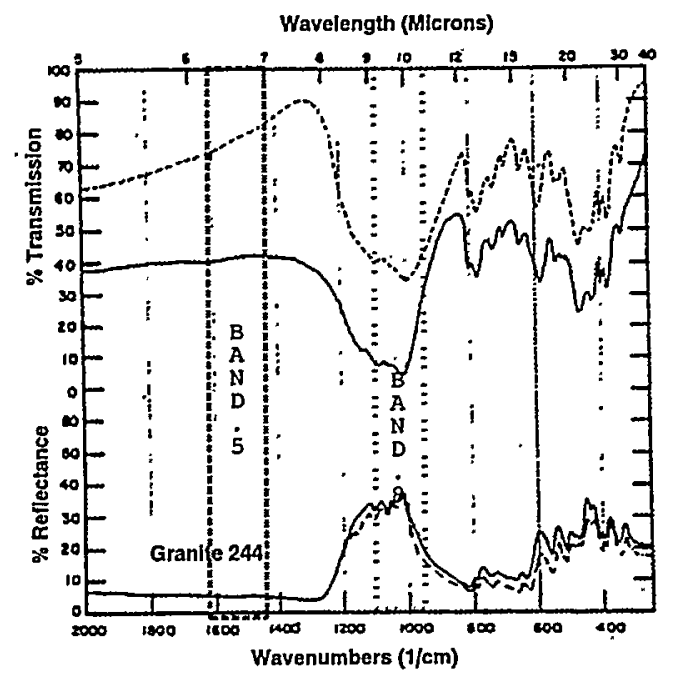

Figure 4b. Spectrum of Granite (after Hunt and Salisbury, 1974.) of the reflectance as measured by bands 5 and 8 shows clear differences between the dark grey siltstone (Similar to argillite) and granite. If we knew how well these laboratory spectra compared to the actual rock spectra, direct identification of the rock type of tailings piles seen in the imagery would be possible. Unfortunately these spectra are only of similar rocks and the composition (and therefore reflection spectra) of the two rock types can vary greatly.

Even if the actual spectra are not known, the laboratory spectra show that a difference in tailings composition is likely to be detected through multispectral means. If the spectral characteristics of tailings are monitored on a regular basis, a change in rock type could be identified as a spectral change and used as a measure of tunnel progress and depth. As a corollary, if tailings of a particular rock type are not identified, a limit of tunnel depth or extent may be determined.

Figure 5 shows an unsupervised categorization of a multispectral data set made up of digitized CIR photographs ( 3 bands: green, red, and NIR) and 3 MSS bands, $(5,8$, and 10). Most of the clusters are given color that mimic the appearance of an NIR photograph. The clusters that represent the tailings from the tunnel are highlighted in yellow. Yellow pixels are found almost exclusively around both tunnel openings in areas where tailings would be found. The distribution of the yellow pixels attests to the unique spectral characteristics of tailings.

Since tailings are frequently removed from the construction site on a regular basis (which is the case here), locating them is an important priority. Spectral identification through categorization of imagery is an excellent means for identification of tailings. For example, Figure 5 show that the tailings are being removed outside the area of the image.

Even the limited imagery used for this study shows the potential of multispectral analysis for spectral characterization. Better data such as complete multispectral imagery with bands designed for material identification or hyperspectral data will give much more precise results.

\section{Multi-Temporal Analysis}

The last section shows how digital multispectral data can be used for multi-temporal analysis. A multi-temporal data set records change in activity, which can contain more information and can be harder to hide than the activity itself.

Figure 6 is an example of a multi-temporal multispectral data set. This image shows difference 


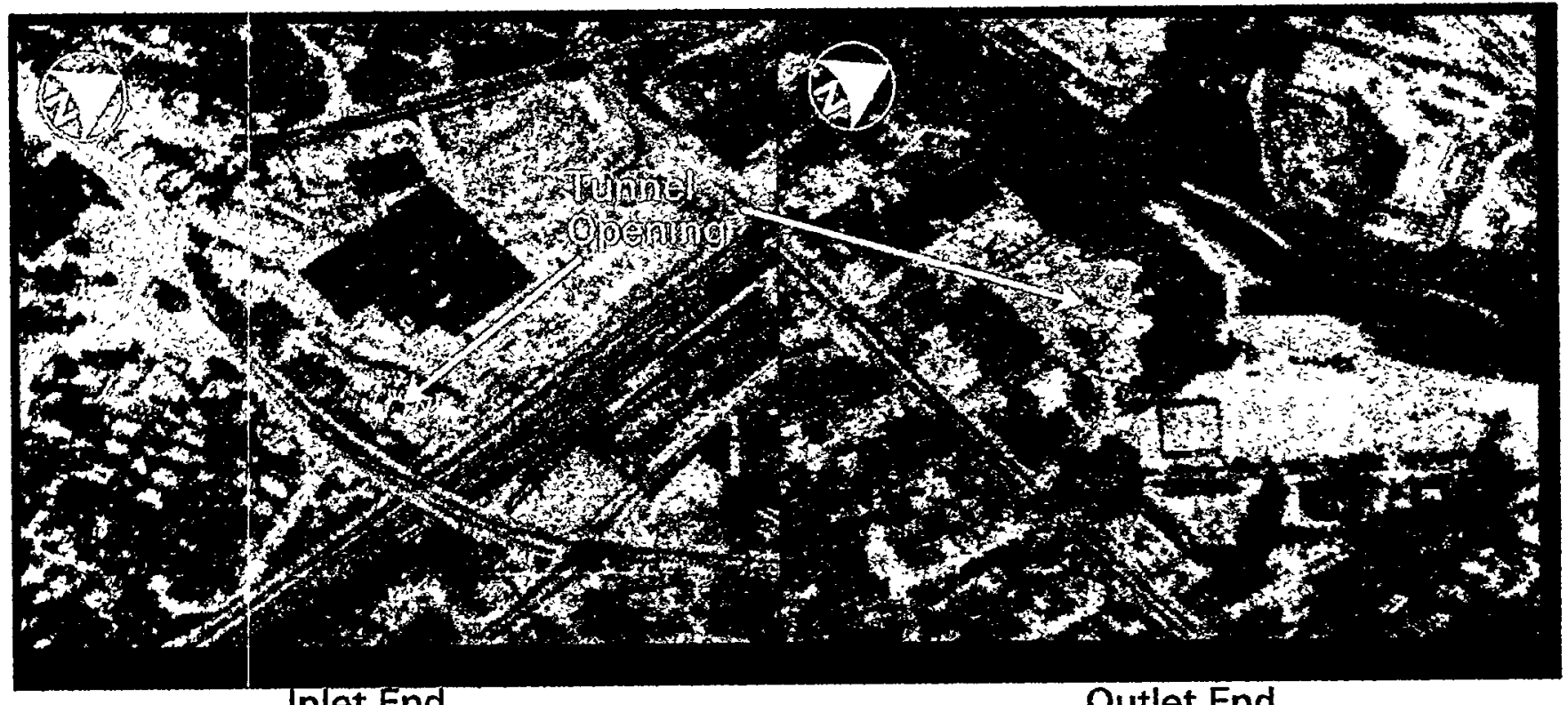

Inlet End

Outlet End

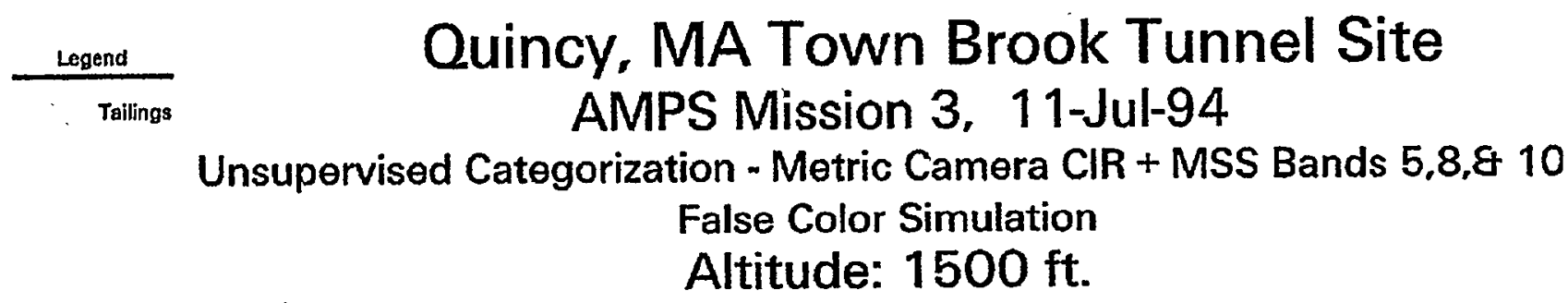

Figure 5. Categorized Image of the Areas Surrounding the Town Brook Tunnel Openings.

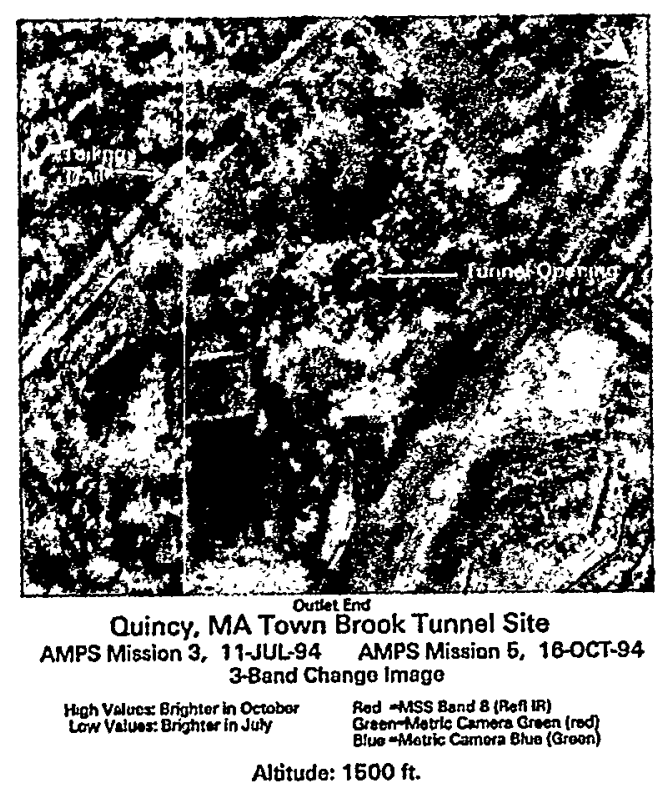

Figure 6.Aulti-Temporal Multispectral Image of the Tunnel Outlet. between July and October activity using three spectral bands. Most changes shown in the image as bright or dark areas are due to non-important changes such as moving shadows and seasonal vegetation variances.

The construction area around the tunnel opening is very cluttered with change. Although this cluttering tends to hide activity, it allows the construction area to stand out from many of the surrounding buildings and fields. The cyan areas at the edges of the construction area show that construction activity has expanded from July to October. Data collections at shorter intervals would allow clearer interpretation of construction activity. Note that the tunnel opening shows no change which is consistent with its relatively unvarying underground environment. The water in Town River bay is similarly unvarying, probably due to its connectivity with the temperature-moderating ocean.

The tailings trail from the construction site is a wealth of information. The fact that the trail is bright and therefore more prevalent in October shows that removal of tailings at the outlet end of the tunnel was much greater after the July data were collected. The Cyan color shows that the spectrum of the tailings is brighter in the green and 


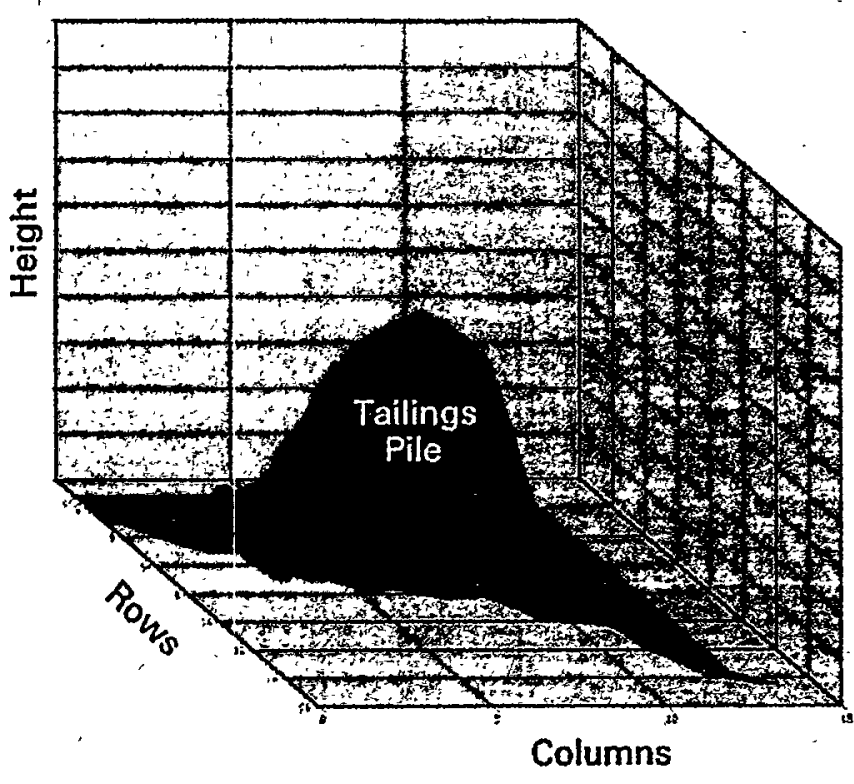

Perspective View of Tailings Pile

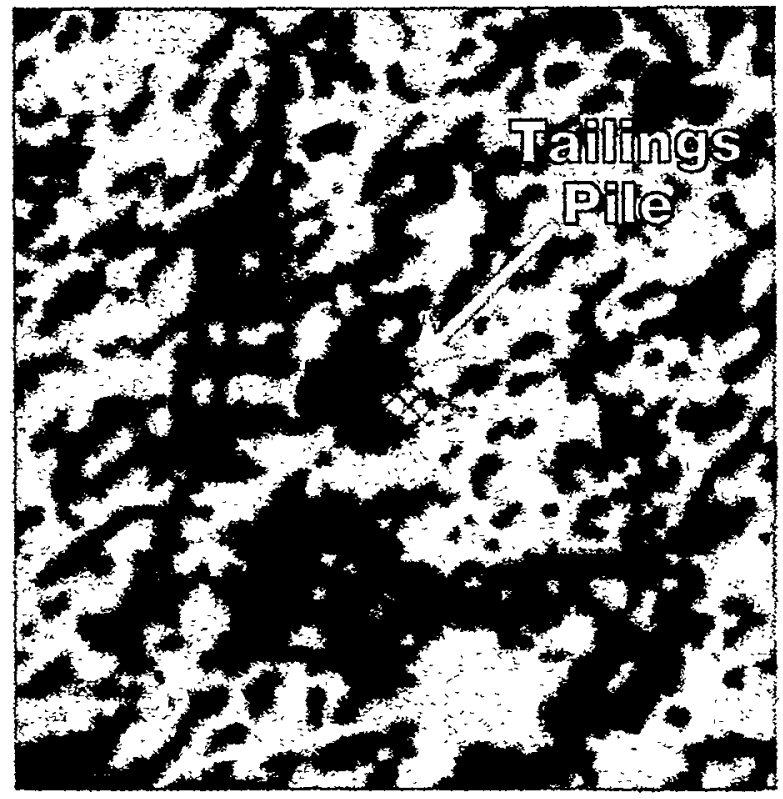

Shaded Relief Image of Surface Elevation

\section{Quincy, MA Town Brook Tunnel Site - Outlet End AMPS Mission 5, 16-OCT-94 \\ Volume Estimation of Excavation Tailings Using DEM Generated From Stereo Imagery.}

Figure 7. Volume Estimation Using a Digital Terrain Model.

red and dark in the infrared (values in this image are relative to the untainted asphalt in the July image). This crude spectrum measurement is consistent the spectra in Figures $4 a$ and $4 \mathrm{~b}$ showing that these lab spectra are similar to the true spectra. The band combination is insufficient to distinguish whether the tailings are granite or argillite. The tailings trail also shows the path along which the tailings are being removed. If this image covered a larger area, this path might lead us to where the tailings are being dumped. The tailings could then analyzed at that location.

\section{Volume Calculation}

The parallax information present in stereo photography can be used to determine the volume in a tailings pile. Commercial software has been available for some time to extract an elevation model from parallax information (Vincent et al., 1988). The volume determined from the elevation model is related to the amount of material removed from the underground excavation.
The right-hand, shaded relief image in Figure 7 is from a digitally produced DEM (Digital Elevation Model) of the construction area around the outlet tunnel opening. A tailings pile has been located within this DEM and has been highlighted in blue. The DEM adds height information to the area information in each photograph allowing volume to be determined. The volume of the tailings pile is depicted as a perspective view in the left image of Figure 7. Using this method the volume of each pile created over a tunnel excavation project can be added to determine the total volume of the tunnel.

\section{Conclusions}

This paper is a demonstration of the capabilities of multispectral, multi-temporal imagery when used toward characterization of a deep tunnel with a minimum of information gathered at the site. The Quincy Town Brook tunnel is an good example of deep tunneling activity, but the data set used for this study could be much improved. To 
truly characterize a site, imagery should be collected using the same spectral bands and areal coverage. Spectral bands should be chosen so materials suspected can be identified by their reflectance spectra. The collections should be made often, and at regular intervals. In the case of this study, tailings are removed daily, so at least daily data collections are needed to keep track of activity and estimate total tailings volume.

In spite of the poor data set, several questions about the site have been answered and methods demonstrated:

- Tunnel openings have been located and identified as belonging to a deep tunnel by their thermal characteristics.

- The tunnel between openings was determined to be deep because of its lack of thermal signature.

- The tailings from tunneling were shown to be spectrally unique and were located at each end of the tunnel. A method was demonstrated to determine what rock was being tunneled.

- Changes in the tunneling operations were detected. These changes include expansion of construction activity and accumulated spillage of tailings as they are being removed.

- A path of tailings removal was identified and the tailings were shown to be removed to an area outside the image area.

- A method of determining tailings volume was demonstrated.

These findings where made from a simple analysis of a rather poor data set. They show how such data can be used to help analysts answer questions about a tunnel such as: "How deep is it?" "How big is it?" and "Where does it go?"

\section{Acknowledgements}

The Authors would like to thank the following colleagues: J.K. Donovan of RSL for creating the map of the Quincy Area (Figure 1), L.K. Balick of RSL for assistance in locating References, and V.J. Murphy of Weston Geophysical for providing background material on the Quincy tunnel Project and U.S Corps of Engineer Documents. I also thank K. Veith of DOE and K.C. Utiger of RSL for thoughtful editing of this document.

\section{References}

Hunt, G.R. and Salisbury, J.W., 1974, "Mid-Infrared Spectral Behavior of Igneous Rocks", Environmental Research Papers, No. 496 AFCRL-TR-74-0625, p. 64.

Hunt, G.R. and Salisbury, J.W., 1975, "Mid-Infrared Spectral Behavior of Sedimentary Rocks.", Environmental Research Papers, No. 520, AFCRL-TR-75-0356, p. 48.

O'Connell, M.F., Wukelic, G.E., Hastings, R.L., Steinmaus, K.L., and Meitzler, W.D., 1995, "Airborne Multisensor Pod System (AMPS) Capabilities, Data Availability, and Mission Opportunities", Proceedings of the Third Thematic Conference on Remote Sensing for Marine and Coastal Environments, Seattle, Washington, pp. 401-412

Rinker, J.N., 1975, "Airborne Infrared Detection of Caves and Crevasses", Photogrammetric Engineering and Remote Sensing, Vol 11, No. 11, pp. 1391-1400.

U.S. Corps of Engineers, 1994, Town Brook Tunnel Local Protection, Quincy, Massachusetts, Design Memorandum, Courtesy of Weston Geophysical, Westboro, MA

Vincent, R.K., Lehman, W.T., Henry, R.L., Herman, J.D., Stivers, M.E., Wilson, M.L., and Etzler, P.J., 1988, "The Application of High Resolution Elevation Models to Petroleum and Mineral Exploration and Production", Proceedings of the Sixth Thematic Conference on Remote Sensing for Exploration Geology, Houston, Texas, Vol. 1, pp. 293-301.

Zilioli, E., Gomarasca, M.A., and Tomasoni, R., 1992, "Application of Terrestrial Thermography to the Detection of Waste-Disposal Sites", Remote Sensing of Environment, Vol 40, pp. 153-160. 